\title{
Correction to: Distinguishing between basic psychological needs and basic wellness enhancers: the case of beneficence as a candidate psychological need
}

\author{
Frank Martela ${ }^{1}$ (D) Richard M. Ryan ${ }^{2}$
}

Published online: 7 February 2020

○) Springer Science+Business Media, LLC, part of Springer Nature 2020

\section{Correction to: Motivation and Emotion https://doi.org/10.1007/s11031-019-09800-x}

The authors would like to correct the following error in the publication of the original article: The appendix 1 was missing and will hereby be added. The appendix contains the four items for the Beneficence frustration scale to assess antisocial impact.

\section{Appendix 1}

Beneficence frustration scale to assess antisocial impact

1. I fear that my actions sometimes cause bad things to other people.
2. Sometimes I feel that I am making other people worse off.

3. I fear that what I do has negative consequences for other people.

4. Sometimes I feel that my impact on people around me is negative.

Publisher's Note Springer Nature remains neutral with regard to jurisdictional claims in published maps and institutional affiliations.

The original article can be found online at https://doi.org/10.1007/ s11031-019-09800-x.

\section{Frank Martela}

frank.martela@aalto.fi

1 School of Business/Department of Industrial Engineering and Management, Aalto University, P.O. Box 15500, 00076 Aalto, Finland

2 Institute for Positive Psychology and Education, Australian Catholic University, 33 Berry Street, North Sydney, NSW, Australia 